\title{
Evaluation of Thrombomodulin Level in Periodontal Pockets
}

\author{
Tugrul Kirtiloglu ${ }^{1 *}$, Ali Caghan Ovali ${ }^{2}$, Serefden Acikgoz ${ }^{3}$, Gokhan Acikgoz ${ }^{1}$ \\ ${ }^{l}$ Department of Period ontology, School of Dentistry, University of Ondokuz Mayis, Samsun, Turkey \\ ${ }^{2}$ Samsun State Dental Hospital, Samsun, Turkey \\ ${ }^{3}$ Department of Medical Biochemistry, School of Medicine, University of Bulent Ecevit, Zonguldak, Turkey \\ *Corresponding Author: Tugrul Kirtiloglu, Department of Period ontology, School of Dentistry, \\ University of Ondokuz Mayis, Samsun, Turkey, Email: tugkir@yahoo.com
}

\begin{abstract}
This study aims to investigate thrombomodulin level in periodontal pockets with respect to its depth. This study included 27 patients, 13 women and 14 men. Probing depth with $5 \mathrm{~mm}$ or more were recorded as deep pockets and probing depth $<5 \mathrm{~mm}$ recorded as shallow pockets. Gingival crevicular fluid was collected with paper strips from 3 deep and 3 shallow pockets of canine to canine tooth in the same patients. The fluid volume in the periopaper strip was calculated with Periotron 8000. Thrombomodulin levels were analyzed byenzyme-linked immunosorbent assay.

There was a significant difference between shallow and deep pockets with respect to the thrombomodulin levels. Increasing of thrombomodulin levels were correlated with shallow pockets, deep pockets and gingival index scores. Thrombomodulin level increases in bleeding sites and inflammation sites of gingival crevicular fluid.
\end{abstract}

Keywords: Bleeding, gingival crevicular fluid, inflammation, thrombomodulin

\section{BACKGROUND}

Thrombomodulin (TM) is an important cofactor for thrombin in circulation to activate protein $\mathrm{C}$ and inhibit coagulation. Thrombomodulin is a cofactor presented on the surfaces of endothelial cells. When thrombin binds to $\mathrm{TM}$, protein $\mathrm{C}$ activation increase 1000 fold [1, 2]. This effect contribute a direct anti-coagulant activity. It means where the thrombomodulin levels increase, bleeding also increased [3]. Previous studies regarding with wound healing reported decrease in TM anticoagulant activity level in epidermis does not appear to alter the reepithelization, but influences collagen production with fibroblasts in the wound matrix $[4,5]$. It was reported that diseased sites of periodontium usually found in the regions where the blot clotting chamber is activated [6]. This activation may be monitored among the molecules found in gingival crevicular fluid (GCF). TM was released from the gingival epithelial cells via neutrophil enzymes in periodontitis patients. The increased level of TM in GCF points out the injury of cell-wall membrane and it may speculate its potential role to ascertain the disease entity [7]. Therefore, relation with $\mathrm{TM}$ in deep and shallow periodontal pockets in the same subject was studied in this study.

\section{Materials}

\subsection{Study Design}

The study was carried out in Department of Periodontology, Ondokuz Mayıs University Dental Faculty. This study was approved by the ethics committee of Ondokuz Mayis University (2008/9) and written informed consent was obtained from the patients. This study included 27 patients, 13 women and 14 men. All of them were non-smokers. Subjects had periodontal disease by multiple sites with a probing depth (PD) of $5 \mathrm{~mm}$ or more and bone loss evaluated by radiographs. Their ages ranged from 31 to 57 years. They were untreated periodontal patients and they had no medical history or any systemic disease. The exclusion criteria were taking antibiotics within the previous 6 months, taking any medications within the previous 3 months, pregnancy or taking oral contraceptive, having less than 20 natural teeth and receiving periodontal therapy within the previous 6 months. Probing depth with $5 \mathrm{~mm}$ or more were recorded as deep pockets and up to $5 \mathrm{~mm}$ recorded as shallow pockets. The periodontitis 
subjects included in this study had shallow and deep pockets in the same mouth and maxillary anterior teeth sites. The remaining all teeth had varying degrees of untreated periodontal disease.

All the clinical data were collected by same examiner. The following periodontal variables were recorded; PD and gingival index (GI) [8]. PD was recorded at six sites per tooth (mesiobuccal, buccal, distobuccal, mesiolingual, lingual, distolingual). PD was obtained from sample sites with the Florida Probe (FP32/7.2.2 version, Florida Probe Corporation, Gainesville, FL, USA). The tip diameter of the probe was $0.45 \mathrm{~mm}$ and the probing force applied was $20 \mathrm{gr}$. The probe was used parallel to the long axis of the teeth.

\subsection{Collection of Samples}

Supragingival plaque was removed and sampling sites were isolated with cotton rolls and sampling sites were air dried to eliminate the contamination of plaque and saliva. A suction pipe was used to prevent salivary contamination of the samples. Each GCF sample was collected with paper strips (Periopaper Strips ${ }^{\circledR}$, Amityville, NY, USA) from selected 3 deep and 3 shallow pockets of maxillary anterior teeth of same patients. The strips were inserted $1 \mathrm{~mm}$ into the crevice for 30 seconds. Paper strips with GCF were immediately transported to Periotron 8000 (Oroflow Inc, Smithtown, NY, USA) for measurement of GCF volume. Periotron 8000 was calibrated with phosphate buffered saline before GCF samples were obtained. Samples contaminated with blood or

Table1: Descriptive values for Pocket depth, Gingival Index and Thrombomodulin

\begin{tabular}{|l|c|c|c|c|c|}
\hline & N & Minimum & Maximum & Mean & SD \\
\hline Shallow Pockets (mm) & 27 & 2.00 & 4.00 & 3.18 & 0.78 \\
\hline Deep Pockets (mm) & 27 & 5.00 & 8.00 & 6.70 & 0.91 \\
\hline Shallow Pockets GI & 27 & 1.00 & 2.00 & 1.39 & 0.36 \\
\hline Deep Pockets GI & 27 & 1.00 & 2.00 & 1.67 & 0.34 \\
\hline Shallow Pockets TM (ng/ml) & 27 & 40.88 & 124.98 & 76.41 & 23.45 \\
\hline Deep Pockets TM (ng/ml) & 27 & 94.56 & 170.83 & 123.48 & 19.72 \\
\hline
\end{tabular}

$S D=$ Standard deviation

Table2: Comparision of the thrombomodulin levels $(\mathrm{ng} / \mathrm{ml})$ between shallow and deep pockets.

\begin{tabular}{|c|c|c|}
\hline Shallow Pockets & \multicolumn{1}{|c|}{ Deep Pockets } & P value \\
\hline $76.4 \pm 23.45$ & $123.4 \pm 19.72$ & $0.000^{*}$ \\
\hline
\end{tabular}
* $p<0.000$

Table3: Correlation of shallow pockets, deep pockets, shallow pockets' GI scores and deep pockets' GI scores with thrombomodulin levels

\begin{tabular}{|l|c|c|c|}
\hline \multirow{2}{*}{} & \multicolumn{3}{|c|}{ Thrombomodulin Levels } \\
\cline { 2 - 4 } & N & r & p \\
\hline Shallow Pockets GI & 27 & $0.703^{*}$ & 0.000 \\
\hline Deep Pockets GI & 27 & $0.604^{*}$ & 0.001 \\
\hline
\end{tabular}




\begin{tabular}{|l|l|l|l|}
\hline Shallow Pockets & 27 & $0.592^{*}$ & 0.001 \\
\hline Deep Pockets & 27 & $0.612^{*}$ & 0.001 \\
\hline
\end{tabular}

*Correlation is significant at the 0.01 level (2-tailed).

\section{DISCUSSION}

We examined the GCF thrombomodulin levels in comparison with shallow and deeper periodontal disease subjects. In this study, thrombomodulin levels were found increased in deep pockets in comparision with shallow pockets. Matsuyama et.al [7] reported that increased thrombomodulin in GCF is related to its enzymatic effect. Destruction of epithelial cells by neutrophil enzymes (cathepsin $\mathrm{G}$ and elastase) cause increasing of TM in the gingival reticular fluid. Authors also reported that the soluble thrombomodulin increased as a result of independent cell death or destruction of epithelial cells. TM values between up to $3 \mathrm{~mm}$ pocket depths and deeper than $3 \mathrm{~mm}$ pocket depths show significant difference. However, TM values increased significantly deeper than 3 $\mathrm{mm}$ regardless of its deepness.

TM is the integral membrane protein located on endothelial cells through the vascular system. Thrombin connects with the thrombomodulin (ratio of 1:1) and this connection dramatically alters the substrate specificity of thrombin [9, 10]. Activated protein $\mathrm{C}$ with this complex causes inhibition of coagulation [2, 11]. TM increased in periodontitis patients at the bleeding and inflammation sites [3]. In the current study, our results showed that TM correlated with GI scores.

Free thrombin effectively binds the fibrinogen but activates the protein $\mathrm{C}$ poorly. In contrast thrombin thrombomodulin complex binds fibrinogen poorly, but activates protein $\mathrm{C}$ effectively $[11,12]$. When there is failure of TM anticoagulant activity, collagen production and fibroblasts are affected due to lack of thrombin and tissue integrity is impaired. Thrombin also connects thrombomodulin which is cell-surface anticoagulant. Thrombomodulin is emerged on the endothelial cells and keratinocytes. It specifically induces the proliferation of endothelial cells and regulates fibrinolysis [13, 14, and 15]. For all these reasons thrombomodulin may play a key role in molecular relations in mechanism of periodontal disease. Furthermore, it is believed that thombomodulin is resistant to cytokines. Apparently, TM is also monitored in nonendothelial tissues in early developmental period brings in mind that it's various functions
[11]. Where the TM increase it is likely that collagen deposition fails [16]. As this sentence capillary fragility is probably increased in these deeper sites due to collagen deposition failing and in consequence the epithelial cell membrane injury may be seen and this probability cause to thrombomodulin increase in GCF.

\section{ACKNOWLEDGEMENT}

This study was supported by the Scientific Research Fund of Ondokuz Mayıs University. The authors report no conflicts of interest related to this study.

\section{REFERENCES}

[1] Esmon NL, Owen WG, Esmon CT. Isolation of a membrane-bound cofactor for thrombincatalyzed activation of protein C. J Biol Chem 1982; 257(14):859-864.

[2] Esmon CT. The roles of protein $\mathrm{C}$ and thrombomodulin in the regulation of blood coagulation. J Biol Chem 1989; 264 (9):47434746.

[3] Matsuyama T, Izumi $Y$, Shibatate $K$, et al. Expression and activity of thrombomodulin in human gingival epithelium: in vivo and in vitro studies. J Periodontal Res 2000; 35(3):146-157.

[4] Peterson JJ, Rayburn HB, Lager DJ, et al. Expression of thrombomodulin and consequences of thrombomodulin deficiency during healing of cutaneous wounds. Am J Pathol 1999; 155(5):1569-1575.

[5] Cheng TL, Wu YT, Lai $\mathrm{CH}$, et al. Thrombomodulin regulates keratinocyte differentiation and promotes wound healing. $\mathbf{J}$ Invest Dermatol 2013(6); 133:1638-1645.

[6] Tatakis DN. Blood coagulation factors in periodontal pathophysiology a review with emphasis on the role of thrombin. Semin Thromb Hemost 1992; 18(1):28-33.

[7] Matsuyama T, Tokuda M, Izumi Y. Significance of thrombomodulin release from gingival epithelial cells in periodontitis patients. $\mathbf{J}$ Periodontal Res 2008; 43(4):379-3 85.

[8] Löe, H. and J. Silness. Periodontal disease in Pregnancy.I. Prevalence and severity. Acta Odontol Scand 1963; 21:533-551.

[9] Sadler JE, Lentz SR, Sheehan JP, Tsiang M, Wu Q. Structure function relationships of the thrombin thrombomodulin interaction. Haemostasis 1993; 23:183-193.

[10] Seguin C, Abid R, Spokes KC, Aird WC. Thrombin down regulates thrombomodulin expression and activity in primary human 
endothelial cells. Endothelium 2008; 15(3):14 3-148.

[11] Esmon CT. Thrombomodulinas model molecular mechanisms that modulate protease specificity and function at the vessel surface. The Faseb Journal 1995; 9(10):946-955.

[12] Vindigni A, White CE, Komives EA, Cera ED. Energetics of thrombin thrombomodulin interaction. Biochemistry 1997; 36(22):6674-6 681.

[13] Mizutani H, Hayashi $T$, Nouchi $N$, et al. Functional and immunoreactive thrombomodulin expressed by keratinocytes. J Invest Dermatol 1994; 103(6):825-828.
[14] Senet P, Peyri N, Berard M, Dubertret L, Boffa MC. Thrombomodulin, a functional surface protein on human keratinocytes, is regulated by retinoic acid. Arch Dermatol Res 1997; 289(3): 151-157.

[15] Artuc M, Hermes B, Algermissen B, Henz BM. Expression of prothrombin, thrombin and its receptors in human scars. Exp Dermatol 2006; 15(7):523-529.

[16] Peterson JJ, Rayburn HB, Lager DJ, et al. Expression of thrombomodulin and consequences of thrombomodulin deficiency during healing of cutaneous wounds. Am J Pathol1999; 155(5):1569-1575.

Citation: Tugrul Kirtiloglu, Ali Caghan Ovali, Serefden Acikgoz, Gokhan Acikgoz. Evaluation of Thrombomodulin Level in Periodontal Pockets. ARC Journal of Dental science. 2020; 5(1):1-4. doi:dx.doi.org/10.20431/2456-0030.0501001.

Copyright: (C) 2020 Authors. This is an open-access article distributed under the terms of the Creative Commons Attribution License, which permits unrestricted use, distribution, and reproduction in any medium, provided the original author and source are credited. 